\title{
Analisa Flash Hider pada Senapan Serbu SS1 V1 dengan Variasi Buffle untuk Menurunkan Intensitas Cahaya (Candela) di Ujung Laras
}

\author{
Simbolido, D. Andrijono* dan Jainur Rohman \\ Jurusan Teknik Mesin, Fakultas Teknik, Universitas Merdeka Malang, Jalan Taman Agung No. 1, Malang, 64146, Indonesia. \\ *Corresponding author email: djoko.andrijono@unmer.ac.id
}

\section{INFORMASI ARTIKEL ABSTRACT}

Diterima: 08 Agustus 2020

Direvisi: 25 Agustus 2020

Disetujui: 26 Agustus 2020

Tersedia online: 14 September 2020

DOI: doi.org/10.26905/jtmt.v16i2.4786

\begin{abstract}
The flash hider is a light weapon component that functions to dampen the flash of fire caused by the burning effect of thrust stuffing. In the event of war at night with the flash hider, the position of the gunner is not visible to the enemy, because the flash of fire at the end of the mouth of the barrel can be suppressed. The flash hider on the SS1 V1 assault rifle, with one buff can reduce the light intensity (candela) by $83.42 \%$. The benefits of research are to provide security for the shooter from being seen by the enemy by installing a flash hider. The aim of this research is to reduce the lower light intensity by using the buffle variation on the flash hider to the large amount of light intensity that comes out at the end of the barrel mouth using one buffle. In conclusion, the light intensity decreased by an average of $83.42 \%$ using the SS1-V1 assault rifle and shooting without using a flash hider was obtained 0.0035 candela. After using a flash hider (one buffle) the decrease was 0.0006 candela. An average reduction in light intensity of $90.857 \%$ using the SS1-V1 assault rifle with shooting without using a flash hider obtained 0.0035 candela and after using a flash hider (buffle variation) a decrease of 0.00032 candela was obtained. Comparison of the percentage value of the decrease in light intensity at the time of shooting using SS1 V1 weapons with flash hider (one buffle) $83.42 \%$ and flashhider (buffle variation) $90.857 \%$.
\end{abstract}

Keywords: Buffle, Illumination Intensity, Light Intensity

\section{A B S T R A K}

Flash hider merupakan komponen senjata ringan berfungsi untuk peredam kilatan cahaya api yang diakibatkan pengaruh pembakaran isian dorong. Apabila terjadi perangpada malam hari dengan adanya flash hider, posisi petembak tidak terlihat oleh musuh, sebab kilatan cahaya api pada ujung mulut laras dapat diredam. Flash hider pada senapan serbu SS1 V1, dengan satu bufflemampu menurunkan intensitas cahaya (candela)83,42 \%.Manfaat penelitian memberikan keamanan bagi penembak agar tidak terlihat oleh musuh dengan memasang flash hider. Tujuan penelitian menurunkan intensitas cahaya yang lebih rendah dengan cara menggunakan variasi buffle pada flash hider terhadap besarnya jumlah intensitas cahaya yang keluar di ujung mulut laras dengan menggunakan satu buffle. Kesimpulan penelitian intensitas cahaya mengalami penurunan rata-rata $83,42 \%$ dengan menggunakan senapan serbu SS1-V1 dan penembakan tanpa menggunakan flash hiderdiperoleh 0,0035 candela. Setelah menggunakan flash hider (satu buffle) diperoleh penurunan menjadi 0,0006 candela. Penurunan intensitas cahaya rata-rata $90,857 \%$ dengan menggunakan senapan serbu SS1-V1dengan penembakan tanpa menggunakan flash hider diperoleh 0,0035 candela dan setelah menggunakan flash hider (variasi buffle) diperoleh penurunan 0,00032 candela.Perbandingan nilai persentase penurunan intensitas cahaya pada saat penembakan menggunakan senjata SS1 V1 yang dipasang flash hider (satu buffle) 83,42\% danflashhider (variasi buffle) $90,857 \%$.

Kata Kunci: Buffle, Intensitas Penerangan, Intensitas Cahaya.

\section{Pendahuluan}

Senjata merupakan alat untuk menembakkan pelor menuju sasaran tertentu. Dalam perang konvensional, pertempuran bukan hanya terjadi pada siang hari, tetapi juga pada malam hari. Pada saat terjadi penembakan, pengaruh cahaya api yang dihasilkan akan sangat tidak efektif apabila hasil dari cahaya 
TRANSMISI Volume 16 Nomor 22020

api ini terlalu terang, hal ini akan membuat kerahasiaan posisi seorang petembak akan diketahui oleh musuh. Dengan demikian memperhatikan intensitas kilatan cahaya api yang muncul akibat pengaruh pembakaran isian dorong, maka diperlukan komponen yang dapat meredam kilatan cahaya api pada senapan serbu SS1V1. Flash hider merupakan komponen senjata ringan berfungsi untuk peredam kilatan cahaya api yang diakibatkan pengaruh pembakaran isian dorong. Apabila terjadi perang pada saat malam hari, diharapkan dengan adanya flash hider, maka posisi petembak tidak akan terlihat oleh musuh, sebab kilatan cahaya api pada ujung mulut laras dapat diredam. Flash hider pada senapan serbu SS1 V1, dengan satu buffle hanya mampu menurunkan intensitas cahaya (candela) sebesar 83,42\%. Untuk menurunkan intensitas cahaya yang lebih kecil, dapat dilakukan dengan cara menggunakan variasi bufflepada flash hiderterhadap besarnya jumlah intensitas cahaya yang keluar diujung mulut laras, sehingga diharapkan akan memperoleh penurunan intensitas cahaya yang lebih kecil daripada hanya menggunakan satu buffle.

\section{Metode Penelitian}

\section{Batasan dan Metode Pengujian}

1. Jenis munisi untuk penembakan.

2. Dimensi bufflepada flash hider.

3. Tekanan gas pada senapan serbu SS1 V1.

4. Intensitas cahaya.

\section{Hasil Rancangan Buffle}

1. Desain Alat

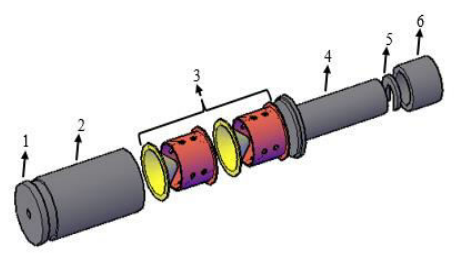

Gambar 1. Desain Alat

Keterangan Gambar 1:

1.Penutup depan.

2.Selubung luar.

3.Buffle.

4.Gun slot.

5.Klem pengunci.

6.Pengunci belakang.

2.Dimensi Komponen Flash Hider

a.Penutup Depan

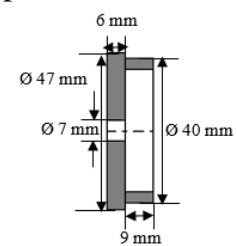

Gambar 2.Penutup Depan.

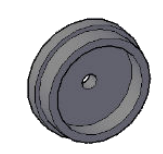

Gambar 3.Tampak Depan.

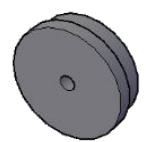

Gambar 4.Tampak Belakang.

b. Selubung Luar

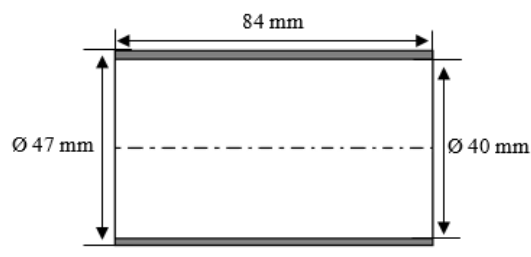

Gambar 5. Selubung Luar.

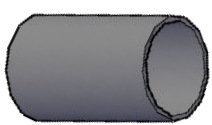

Gambar 6.Tampak Samping

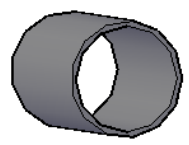

Gambar 7.Tampak Depan

c.Buffle

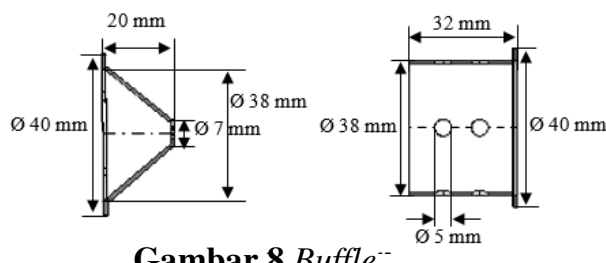

Gambar 8.Buffle-

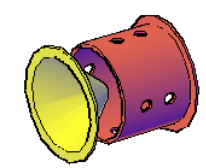

Gambar 9. Tampak Samping

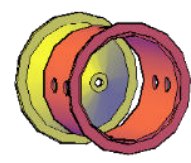

Gambar 10.Tampak Belakang

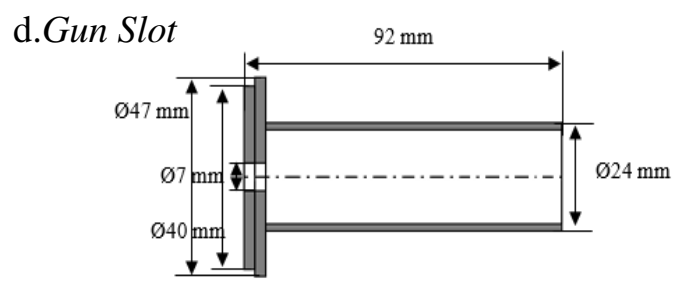

Gambar 11.Gun Slot 
TRANSMISI Volume 16 Nomor 12020

Tabel 2. Data Hasil Pengujian Intensitas Penerangan (Lux) Penembakan tanpa Menggunakan Flash Hider.

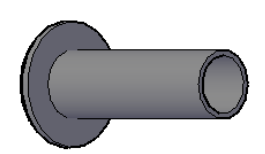

Gambar 12.Tampak Belakang.

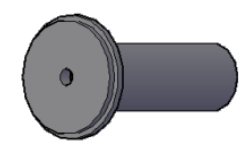

Gambar 13.Tampak Depan.

e.Klem Pengunci

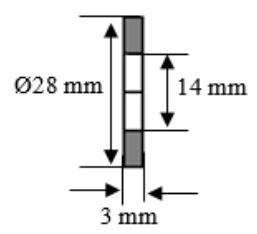

Gambar 14. Klem Pengunci

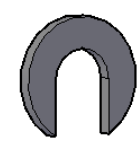

Gambar 15.Tampak Samping.

f.Pengunci Belakang.

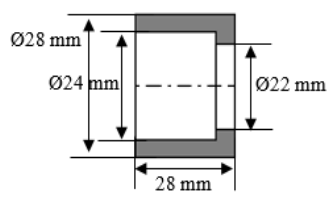

Gambar 16.Pengunci Belakang

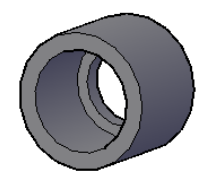

Gambar 17. Tampak Depan

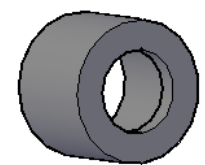

Gambar 18. Tampak Belakang

\section{Hasil dan Pembahasan}

1. Data Hasil Pengujian Intensitas Penerangan (Lux) Penembakan tanpa Menggunakan Flash Hider

\begin{tabular}{|c|c|c|c|}
\hline \multirow{2}{*}{ No } & \multirow{2}{*}{$\begin{array}{c}\text { Urutan } \\
\text { Penembakan }\end{array}$} & Intensitas Penerangan (Lux) & \multirow{2}{*}{ Ket } \\
\cline { 3 - 3 } & $\mathbf{2}$ & $\mathbf{3}$ & \\
\hline $\mathbf{1}$ & $\mathbf{2}$ & 10 & $\mathbf{4}$ \\
\hline 1. & 1 & 8 & \\
\hline 2. & 2 & 8 & \\
\hline 3. & 3 & 9 & \\
\hline 4. & 4 & 10 & \\
\hline 5. & 5 & 8 & \\
\hline 6. & 6 & 9 & \\
\hline 7. & 7 & 10 & \\
\hline 8. & 8 & 8 & \\
\hline 9. & 9 & 9 & \\
\hline 10. & 10 & & \\
\hline
\end{tabular}

2. Data Hasil Pengujian Intensitas Penerangan (Lux) Penembakan dengan Menggunakan Flash Hider(Satu Buffle)

Tabel 3. Data Hasil Pengujian Intensitas Penerangan (Lux) Penembakan dengan Menggunakan Flash Hider(Satu Buffle)

\begin{tabular}{|c|c|c|c|}
\hline \multirow{2}{*}{ No } & \multirow{2}{*}{$\begin{array}{c}\text { Urutan } \\
\text { Penembakan }\end{array}$} & Intensitas Penerangan (Lux) & \multirow{2}{*}{ Ket } \\
\cline { 3 - 3 } $\mathbf{1}$ & $\mathbf{2}$ & $\mathbf{3}$ & \\
\hline 1. & 1 & 2 & $\mathbf{4}$ \\
\hline 2. & 2 & 1 & \\
\hline 3. & 3 & 1 & \\
\hline 4. & 4 & 2 & \\
\hline 5. & 5 & 2 & \\
\hline 6. & 6 & 1 & \\
\hline 7. & 7 & 2 & \\
\hline 8. & 8 & 2 & \\
\hline 9. & 9 & 1 & \\
\hline 10. & 10 & 2 & \\
\hline
\end{tabular}

3. Data Hasil Pengujian Intensitas Penerangan (Lux) Penembakan dengan Menggunakan flash hider(variasi buffle)

Tabel 4. Data Hasil Pengujian Intensitas Penerangan (Lux) Penembakan dengan Menggunakan flash hider(variasi buffle)

\begin{tabular}{|c|c|c|c|}
\hline \multirow{2}{*}{ No } & \multirow{2}{*}{$\begin{array}{c}\text { Urutan } \\
\text { Penembakan }\end{array}$} & Intensitas Penerangan (Lux) & \multirow{2}{*}{ Ket } \\
\cline { 3 - 3 } & $\mathbf{2}$ & $\mathbf{3}$ & $\mathbf{4}$ \\
\hline $\mathbf{1}$ & 1 & 1 & \\
\hline 1. & 2 & 1 & \\
\hline 2. & 3 & 0 & \\
\hline 3. & 4 & 1 & \\
\hline 4. & 5 & 0 & \\
\hline 5. & 6 & 1 & \\
\hline 6. & 7 & 2 & \\
\hline 7. & 7 & 1 & \\
\hline 8. & 8 & 1 & \\
\hline 9. & 9 & 0 & \\
\hline 10. & 10 & & \\
\hline
\end{tabular}

4.Data Karakteristik Flash Hider
a. Panjang
: $87 \mathrm{~mm}$.
b. Diameter tabung $\quad: 47 \mathrm{~mm}$.
c.Bahan : Stainless Steel.
d.Massa flash hider :
Satu Buffle) $\quad: 793$ gram.
Variasi Buffle) $\quad: 812$ gram. 
e. Jumlah Lubang Buffle:

1) Flash Hider (Satu Buffle) : 14 Lubang.

2) Flash Hider (Variasi Buffle) : 16 Lubang.

\section{Analisa Perhitungan}

1.Analisa Tekanan Gas di Ujung Mulut Laras

a. Luas penampang laras:

$A=1 / 4 \cdot \pi \cdot d^{2}=1 / 4 \cdot 3,14 \cdot\left(5,56 \mathrm{~mm} \times 10^{-3}\right)^{2}$

$\mathrm{A}=0,000024267176 \mathrm{~m}^{2}$

b.Tekanan Gas Rata-Rata di dalam Laras:

$$
\begin{aligned}
& \overline{\mathrm{p}}=\frac{\mathrm{mp}+\mathrm{smc}}{2 \mathrm{se}} \mathrm{Ve}^{2} \\
& \overline{\mathrm{p}}=\frac{2,0,004 \mathrm{R} g+0,5.0,00169 \mathrm{Kg}}{2.0,449 \mathrm{~m}, 0,000024267176 \mathrm{~m}^{2}} \times(989 \mathrm{~m} / \mathrm{dt})^{2} \\
& \overline{\mathrm{p}}=\frac{0,004845 \mathrm{Kg}}{0,000021791924 \mathrm{~m}^{2}} \times 978121 \mathrm{~m}^{2} \mathrm{dH}^{2} \\
& \overline{\mathrm{p}}=217465710 \mathrm{~Pa}=2174,65710 \mathrm{bar}
\end{aligned}
$$

c. Perbandingan Tekanan Gas

Perhitungan perbandingan tekanan gas:

$$
\eta \mathrm{p}=\frac{\mathrm{p}}{\mathrm{p}_{\operatorname{mals}}}=\frac{2174,65710 \mathrm{Bar}}{3800 \mathrm{Bar}}=0,5722
$$

d. Tekanan Gas Di Ujung Mulut Laras

Tekanan gas diujung mulut laras dihitung dengan rumus: $\mathrm{P}_{\mathrm{e}}=\overline{\mathrm{p}} \cdot \pi(\eta \mathrm{p})$

dimana: untuk harga $\eta p=0,5722$, maka besarnya $\pi(\eta p)$ diperoleh dengan cara interpolasi (tabel Heydenrich 1):

\begin{tabular}{|c|c|}
\hline $\boldsymbol{\eta p}$ & $\boldsymbol{\pi ( \eta \mathbf { p } )}$ \\
\hline 0,50 & 0,382 \\
\hline $\mathbf{0 , 5 7}$ & $\mathbf{0 , 4 4 0 8}$ \\
\hline 0,60 & 0,466 \\
\hline
\end{tabular}

$\mathrm{P}_{\mathrm{e}}=2174,65710$ bar $\mathrm{x} 0,4408$

$\mathrm{P}_{\mathrm{e}}=958,5888497$ bar $=95858884,97 \mathrm{~Pa}$, makatekanan gas di ujung mulut laras (tanpa kompensator) sebesar 95858884,97 Pa.

2. Tekanan Gas di Ujung Flash Hider

a. Perhitungan Volume Flash Hider

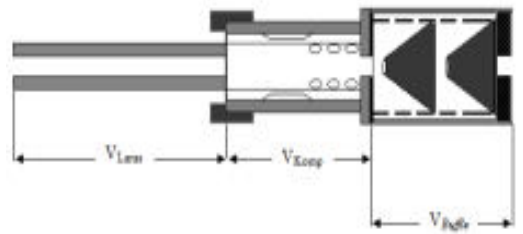

Gambar 19. Volume Flash Hider

Untuk perhitungan volume laras $\left(\mathrm{V}_{\text {Laras }}\right)$ :

$$
P_{1} \cdot V_{1}=P_{2} \cdot V_{2}
$$

dimana :

$$
\mathrm{V}=\mathrm{A} \cdot \mathrm{Se}
$$

maka :

$$
\begin{aligned}
& V=0,000024267176 \mathrm{~m}^{2} \cdot 0,449 \mathrm{~m} \\
& V=0,000010895 \mathrm{~m}^{3}=10,895 \mathrm{ml}
\end{aligned}
$$

Tabel 5. Data Volume Flash Hider

\begin{tabular}{|c|c|c|c|}
\hline No & Flash Hider & (ml) & Keterangan \\
\hline 1 & V $_{\text {Laras }}$ & 10,895 & Hasil dari perhitungan \\
\hline 2 & $V_{\text {Komp }}$ & 10,5 & \multirow{2}{*}{ Hasil dari pengukuran } \\
\hline 3 & V $_{\text {Bufflel }}$ & 60 & \\
\hline 4 & $\mathrm{~V}_{\text {Buffle } 2}$ & 134,7 & \\
\hline
\end{tabular}

b.Perhitungan Tekanan Gas di Ujung Kompensator $\left(\mathrm{P}_{\text {Komp }}\right)$

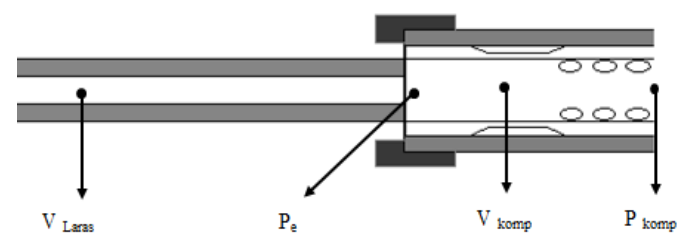

Gambar 20. Volume, Tekanan Gas pada Laras dan Kompensator

Untuk perhitungan tekanan gas di ujung kompensator $\left(\mathrm{P}_{\text {Komp }}\right)$ :

$$
\mathrm{P}_{1} \cdot \mathrm{V}_{1}=\mathrm{P}_{2} \cdot \mathrm{V}_{2}
$$

dimana :

$$
\begin{aligned}
& \mathrm{P}_{1}=\mathrm{P}_{\mathrm{e}}=958,5888497 \mathrm{bar} \\
& \mathrm{V}_{1}=\mathrm{V}_{\text {Laras }}=10,895 \mathrm{ml} \\
& \mathrm{P}_{2}=\mathrm{P}_{\text {Komp }} \\
& \mathrm{V}_{2}=\mathrm{V}_{\text {Laras }}+\mathrm{V}_{\text {Kompensator }} \\
& \mathrm{V}_{2}=10,895 \mathrm{ml}+10,5 \mathrm{ml} \\
& \mathrm{V}_{2}=21,395 \mathrm{ml}
\end{aligned}
$$

maka besarnya tekanan gas di ujung kompensator $\left(\mathrm{P}_{\text {Komp }}\right)$ :

$$
\begin{gathered}
\mathrm{P}_{1} \cdot \mathrm{V}_{1}=\mathrm{P}_{2} \cdot \mathrm{V}_{2} \\
\mathrm{P}_{\mathrm{e}} \cdot \mathrm{V}_{\text {Laras }}=\mathrm{P}_{\text {Komp }} \cdot \mathrm{V}_{2} \\
\mathrm{P}_{\text {Komp }}=\left(\mathrm{P}_{\mathrm{e}} \cdot \mathrm{V}_{\text {Laras }}\right) / \mathrm{V}_{2} \\
\mathrm{P}_{\text {Komp }}=(958,5888497 \text { bar } .10,895 \mathrm{ml}) / 21,395 \mathrm{ml} \\
\mathrm{P}_{\text {Komp }}=488,143282 \text { bar }
\end{gathered}
$$

c. Perhitungan Tekanan Gas di Ujung Buffle $\left(\mathrm{P}_{\text {Buffle }}\right)$

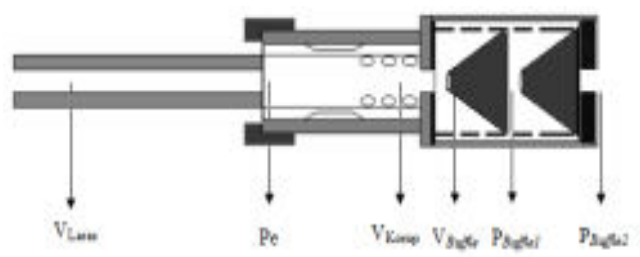

Gambar 21. Volume, Tekanan Gas pada Laras dan Buffle

1. Perhitungan Tekanan Gas Di UjungBuffle1 $\left(\mathrm{P}_{\text {Buffle }}\right)$ :

$$
\mathrm{P}_{1} \cdot \mathrm{V}_{1}=\mathrm{P}_{2} \cdot \mathrm{V}_{2}
$$

dimana:

$$
\begin{gathered}
\mathrm{P}_{1}=\mathrm{P}_{\mathrm{e}}=958,5888497 \text { Bar } \\
\mathrm{V}_{1}=\mathrm{V}_{\text {Laras }}=10,895 \\
\mathrm{P}_{2}=\mathrm{P}_{\text {Buffle }} \\
\mathrm{V}_{2}=\mathrm{V}_{\text {Laras }}+\mathrm{V}_{\text {Kompensator }}+\mathrm{V}_{\text {Buffle I }} \\
\mathrm{V}_{2}=10,895+10,5+67 \\
\mathrm{~V}_{2}=88,395 \mathrm{ml}
\end{gathered}
$$

maka besarnya tekanan gas di ujung Buffle $\left(\mathrm{P}_{\text {Buffle }}\right)$ : 
$\mathrm{P}_{1} \cdot \mathrm{V}_{1}=\mathrm{P}_{2} \cdot \mathrm{V}_{2}$

$$
\begin{aligned}
& \mathrm{P}_{\mathrm{e}} \cdot \mathrm{V}_{\text {Laras }}=\mathrm{P}_{\text {Bufflel }} \cdot \mathrm{V}_{2} \\
& \mathrm{P}_{\text {Buffle }}=\left(\mathrm{P}_{\mathrm{e}} \cdot \mathrm{V}_{\text {Laras }}\right) / \mathrm{V}_{2} \\
& \mathrm{P}_{\text {Buffle } 1}=(958,5888497 \text { Bar .10,895 ml }) / 88,395 \mathrm{ml} \\
& \mathrm{P}_{\text {Buffle } 1}=118,149505 \text { Bar }
\end{aligned}
$$

2. Perhitungan Tekanan Gas Di Ujung Buffle $\left(\mathrm{P}_{\text {Buffle }}\right)$ :

$$
\mathrm{P}_{1}, \mathrm{~V}_{1}=\mathrm{P}_{2} \cdot \mathrm{V}_{2}
$$

dimana :

$$
\begin{aligned}
& \mathrm{P}_{1}=\mathrm{P}_{\mathrm{e}}=958,5888497 \mathrm{Bar} \\
& \mathrm{V}_{1}=\mathrm{V}_{\text {Laras }}=10,895 \\
& \mathrm{P}_{2}=\mathrm{P}_{\text {Buffle } 2} \\
& \mathrm{~V}_{2}=\mathrm{V}_{\text {Laras }}+\mathrm{V}_{\text {Kompensator }}+\mathrm{V}_{\text {Buffle } 2} \\
& \mathrm{~V}_{2}=10,895+10,5+134,7 \\
& \mathrm{~V}_{2}=156,095 \mathrm{ml}
\end{aligned}
$$

maka besarnya tekanan gas di ujung Buffle $\left(\mathrm{P}_{\text {Buffle }}\right)$ :

$$
\begin{aligned}
& \mathrm{P}_{1} \cdot \mathrm{V}_{1}=\mathrm{P}_{2} \cdot \mathrm{V}_{2} \\
& \mathrm{P}_{\mathrm{e}} \cdot \mathrm{V}_{\text {Laras }}=\mathrm{P}_{\text {Buffle } 2} \cdot \mathrm{V}_{2} \\
& \mathrm{P}_{\text {Buffle } 2}=\left(\mathrm{P}_{\mathrm{e}} \cdot \mathrm{V}_{\text {Laras }}\right) / \mathrm{V}_{2} \\
\mathrm{P}_{\text {Buffle2 } 2} & =(958,5888497 \text { Bar } .10,895 \mathrm{ml}) / 156,095 \mathrm{ml} \\
& \mathrm{P}_{\text {Buffle }}=66,918 \text { Bar }
\end{aligned}
$$

d. Perhitungan Kecepatan Pelor pada Flash Hider

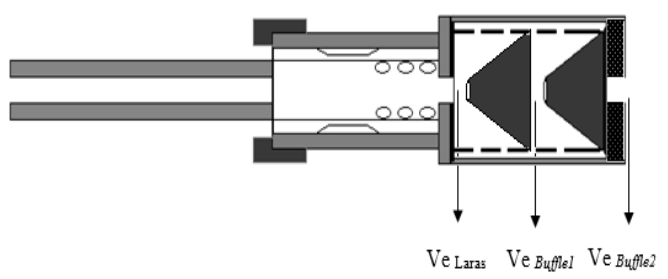

Gambar 22. Kecepatan Pelor pada Flash Hider

1. Perhitungan Kecepatan Pelor di Ujung Buffle1 $\left(\mathrm{Ve}_{\text {Buffle } 1}\right)$ :

$$
\mathrm{Ve}=\sqrt{\frac{2 \cdot E}{m p}}
$$

dimana :

$$
\begin{aligned}
& \mathrm{E}_{\text {Total }}=\mathrm{E}_{2}+\mathrm{E}_{3} \\
& \mathrm{E} \quad={ }_{1} / 2 \cdot \mathrm{mp} \cdot \mathrm{Ve}^{2} \\
& \mathrm{E}_{1}=\mathrm{P}_{1} \cdot \mathrm{V}_{1}
\end{aligned}
$$

maka :

$$
\begin{aligned}
& \mathrm{E}_{\text {Total }}=\left(\mathrm{P}_{\text {Komp }} \cdot \mathrm{V}_{2}\right)+\left(\mathrm{P}_{\text {Bufflel }} \cdot \mathrm{V}_{3}\right) \\
& 1 / 2 \cdot \mathrm{mp} \cdot \mathrm{Ve}^{2}=\left(\mathrm{P}_{\text {Komp }} \cdot \mathrm{V}_{2}\right)+\left(\mathrm{P}_{\text {Bufflel }} \cdot \mathrm{V}_{3}\right) \\
& 1 / 2 \cdot \mathrm{mp} \cdot \mathrm{Ve}^{2}=(48814328,2 \mathrm{~Pa} \cdot 10,5 \mathrm{ml})+ \\
& (11814950,5 \mathrm{~Pa} \cdot 67 \mathrm{ml}) \\
& 1 / 2 \cdot \mathrm{mp} \cdot \mathrm{Ve}^{2}=(512,5504461 \mathrm{~J})+(791,6016835 \mathrm{~J}) \\
& \mathrm{Ve}_{\text {Buffle }} \quad=\sqrt{\frac{2 \cdot \boldsymbol{E}}{m p}}
\end{aligned}
$$

$$
\begin{array}{ll}
\mathrm{Ve}_{\text {Bufflel }} & =\sqrt{\frac{2 \cdot 1304,1521296 \mathrm{~J}}{0,004 \mathrm{Kg}}} \\
\mathrm{Ve}_{\text {Bufflel }} & =\sqrt{652076,0648 \mathrm{~m} / \mathrm{dt}} \\
\mathrm{Ve}_{\text {Bufflel }} & =807,51226913 \mathrm{~m} / \mathrm{dt}
\end{array}
$$

2. Perhitungan Kecepatan Pelor di Ujung Buffle2 ( $\left(\mathrm{Ve}_{\text {Buffle } 2}\right)$ :

$$
\mathrm{Ve}=\sqrt{\frac{2 \cdot E}{m p}}
$$

dimana :

$$
\begin{array}{ll}
\mathrm{E}_{\text {Total }}= & \mathrm{E}_{3}+\mathrm{E}_{4} \\
\mathrm{E} & ={ }^{1} / 2 \cdot \mathrm{mp} \cdot \mathrm{Ve}^{2} \\
\mathrm{E}_{1} & =\mathrm{P}_{1} \cdot \mathrm{V}_{1}
\end{array}
$$

maka :

$\mathrm{E}_{\text {Total }}=\left(\mathrm{P}_{3} \cdot \mathrm{V}_{3}\right)+\left(\mathrm{P}_{4} \cdot \mathrm{V}_{4}\right)$

$1 / 2 \cdot \mathrm{mp} \cdot \mathrm{Ve}^{2}=\left(\mathrm{P}_{\text {Buffle } 1} \cdot \mathrm{V}_{3}\right)+\left(\mathrm{P}_{\text {Buffle2 }} \cdot \mathrm{V}_{4}\right)$

$1 / 2 \cdot \mathrm{mp} \cdot \mathrm{Ve}^{2}=(11814950,5 \mathrm{~Pa} \cdot 67 \mathrm{ml})+$

$(6691800 \mathrm{~Pa} .67,7 \mathrm{ml})$

$1 / 2 \cdot m p \cdot \mathrm{Ve}^{2}=(791,6016835 \mathrm{~J})+(453,03486 \mathrm{~J})$

$\mathrm{Ve}_{\text {Buffle } 2}=\sqrt{\frac{2 . E}{m p}}=\sqrt{\frac{2.1244,6265475 J}{0,004 \mathrm{Kg}}}$

$\mathrm{Ve}_{\text {Buffle } 2}=\sqrt{622318,27175 \mathrm{~m} / \mathrm{dt}}=788,8715179 \mathrm{~m} / \mathrm{detik}$

Dengan perhitungan yang sama, hasilnya ditunjukkan pada Tabel 6.

Tabel 6.Rekapitulasi Hasil Perhitungan Perubahan Tekanan Gas pada Buffle di Flash Hider.

\begin{tabular}{c|c|c|c|c|}
\hline No & $\begin{array}{c}\text { Nama } \\
\text { Komponen }\end{array}$ & Volume (ml) & $\begin{array}{c}\text { Tekanan Gas } \\
\text { (Bar) }\end{array}$ & $\begin{array}{c}\text { Kecepatan Pelor } \\
(\mathbf{m} / \mathbf{d t})\end{array}$ \\
\hline 1 & Laras & 10,895 & 958,5888497 & 989 \\
\hline 2 & Bufflel & 67 & 118,149505 & 807,51226913 \\
\hline 3 & Buffle2 & 134,7 & 66,918 & 788,8715179 \\
\hline
\end{tabular}

4. Analisa Perhitungan Intensitas Cahaya (Candela). Berdasarkan hasil pengujian, dimana Intensitas Penerangan (Lux) tanpa menggunakan flash hideradalah 10 Lux dan intensitas penerangan (Lux) dengan menggunakan Flash Hider adalah untuk Satu Buffle sebesar 2 Lux dan untuk Variasi Buffle1 Lux, maka hasil intensitas cahaya (Candela) dengan rumus:

a. Perhitungan Intensitas Cahaya (candela) Tanpa Menggunakan Flash Hider.

$$
\begin{aligned}
\mathrm{Ep} & =\frac{\mathrm{I}}{\mathrm{d}^{2}} \\
\mathrm{~L} & =\mathrm{Ep} \cdot \mathrm{d}^{2} \\
\mathrm{~L} & =10 \text { Lux. }(0,02)^{2} \mathrm{~m} \\
\mathrm{l} & =0,004 \text { candela. }
\end{aligned}
$$

Jadi besarnya intensitas cahaya (candela) tanpa menggunakan flash hiderpada penembakan pertama sebesar 0,004 candela. Dengan cara yang sama diperoleh hasil sebagai berikut:

Tabel 7.RekapitulasiPerhitungan Intensitas Cahaya (Candela) tanpa menggunakan Flash Hider 
TRANSMISI Volume 16 Nomor 22020

\begin{tabular}{|c|c|c|c|c|}
\hline No & Uji ke & $\begin{array}{c}\text { Intensitas Penerangan } \\
\text { (Lux) }\end{array}$ & $\mathbf{d}$ & $\begin{array}{c}\text { Intensitas Cahaya } \\
\text { (Candela) }\end{array}$ \\
\hline 1 & 1 & 10 & 0,02 & 0,004 \\
\hline 2 & 2 & 8 & 0,02 & 0,0032 \\
\hline 3 & 3 & 8 & 0,02 & 0,0032 \\
\hline 4 & 4 & 9 & 0,02 & 0,0036 \\
\hline 5 & 5 & 10 & 0,02 & 0,004 \\
\hline 6 & 6 & 8 & 0,02 & 0,0032 \\
\hline 7 & 7 & 10 & 0,02 & 0,004 \\
\hline 8 & 8 & 9 & 0,02 & 0,0036 \\
\hline 9 & 9 & 8 & 0,02 & 0,0032 \\
\hline 10 & 10 & 9 & 0,02 & 0,0036 \\
\hline \multicolumn{2}{|r|}{ Rata-rata } & 8,9 & 0,02 & 0,0035 \\
\hline
\end{tabular}

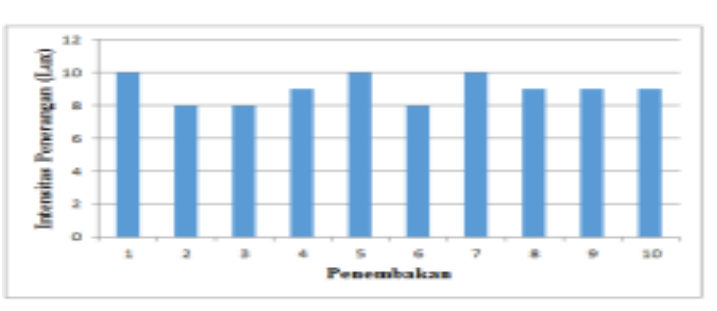

Grafik 1. IntensitasPenerangan tanpa Menggunakan Flash Hider

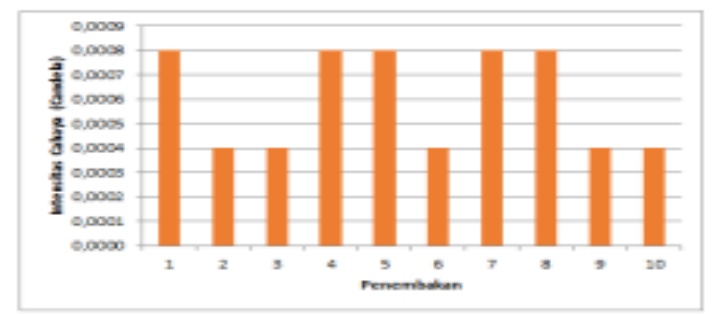

Grafik 2. Intensitas Cahaya dengan Menggunakan Flash Hider(Satu Buffle)

b. Perhitungan Intensitas Cahaya (Candela) dengan Menggunakan Flash Hider (Satu Buffle).

$$
\begin{aligned}
& \text { Ep }=\frac{I}{d^{2}} \\
& l=\quad \text { Ep } \cdot d^{2}
\end{aligned}
$$

$1=2$ Lux. $(0,02)^{2} \mathrm{~m}=0,0008$ candela, makabesarnya intensitas cahaya (candela) dengan menggunakan flash hiderpada penembakan pertama adalah sebesar 0,0008 candela. Perhitungan selanjutnya dengan rumus yang sama hasilnya ditunjukkan pada Tabel 8 .

Tabel 8. Data Rekapitulasi Perhitungan Intensitas Cahaya (Candela) dengan menggunakan Flash Hider (Satu Buffle).

\begin{tabular}{|c|c|c|c|c|}
\hline No & Uji ke & $\begin{array}{c}\text { Intensitas Penerangan } \\
\text { (Lux) }\end{array}$ & $\mathbf{d}$ & $\begin{array}{c}\text { Intensitas Cahaya } \\
\text { (Candela) }\end{array}$ \\
\hline 1 & 1 & 2 & $\mathbf{0 , 0 2}$ & 0,0008 \\
\hline 2 & 2 & 1 & 0,02 & 0,0004 \\
\hline 3 & 3 & 1 & 0,02 & 0,0004 \\
\hline 4 & 4 & 2 & 0,02 & 0,0008 \\
\hline 5 & 5 & 2 & 0,02 & 0,0008 \\
\hline 6 & 6 & 1 & 0,02 & 0,0004 \\
\hline 7 & 7 & 2 & 0,02 & 0,0008 \\
\hline 8 & 8 & 2 & 0,02 & 0,0008 \\
\hline 9 & 9 & 1 & 0,02 & 0,0004 \\
\hline 10 & 10 & 1 & 0,02 & 0,0004 \\
\hline Rata-rata & 1,5 & $\mathbf{0 , 0 2}$ & 0,0006 \\
\hline
\end{tabular}

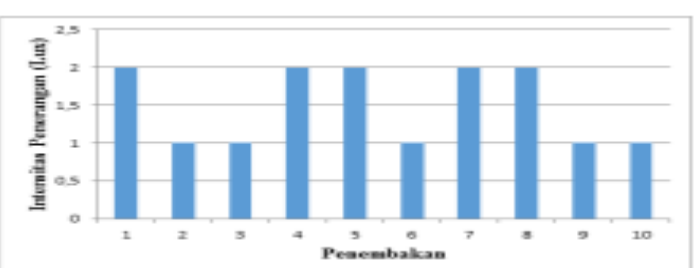

Grafik 3. Intensitas Penerangan (Lux) dengan Menggunakan Flash Hider(Satu Buffle)

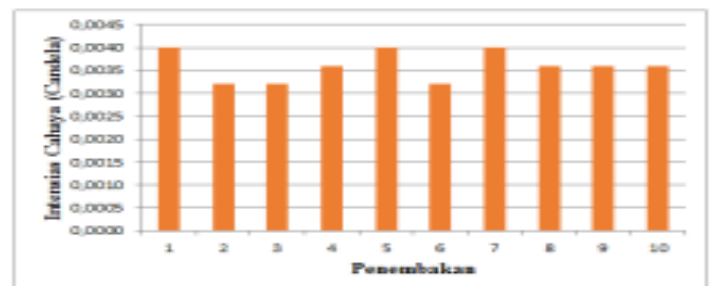

Grafik 4. Intensitas Cahaya tanpa Menggunakan Flash Hider

c. Perhitungan Intensitas Cahaya (Candela) dengan Menggunakan Flash Hider (Variasi Buffle).

$$
\begin{aligned}
& \mathrm{Ep}=\frac{\mathrm{I}}{\mathrm{d}^{2}} \\
& \mathrm{~L}=\mathrm{Ep} \cdot \mathrm{d}^{2}
\end{aligned}
$$

$1=1$ Lux. $(0,02)^{2} \mathrm{~m}=0,0004$ candela.

Jadi besarnya intensitas cahaya (candela) dengan menggunakan flash hiderpada penembakan pertama adalah 0,0004 candela. Perhitungan selanjutnya dengan rumus yang sama, hasilnya ditunjukkan pada Tabel 9.

Tabel 9. Data RekapitulasiPerhitungan Intensitas Cahaya (Candela) dengan Menggunakan Flash Hider (Variasi Buffle).
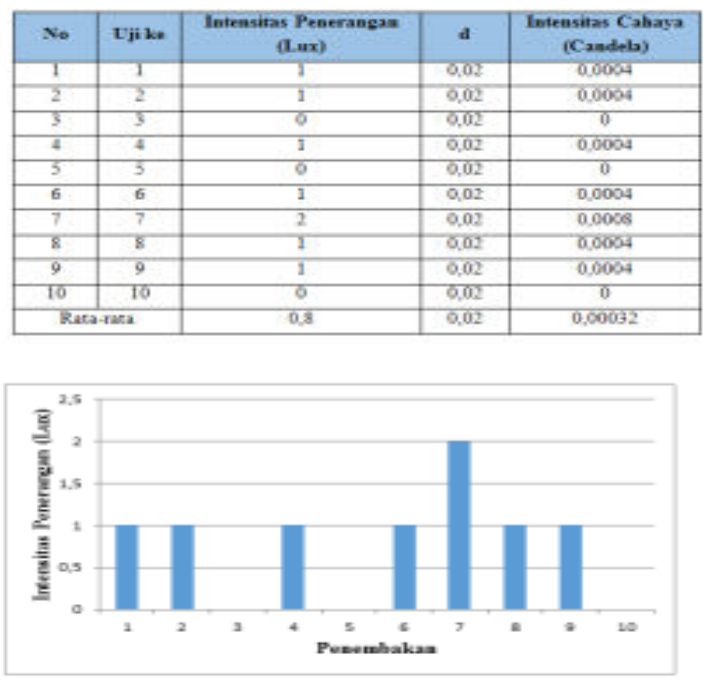

Grafik 4. IntensitasPenerangan (Lux) versus Flash Hider (Variasi Buffle)

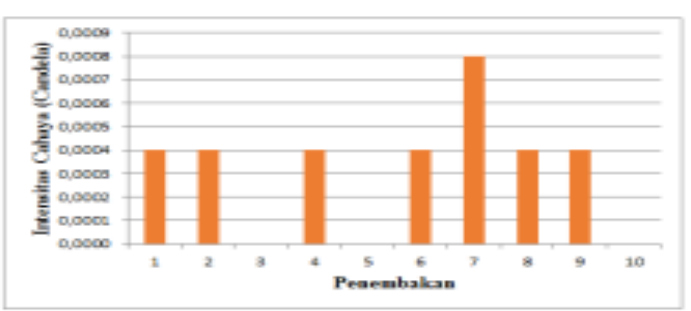

Grafik 5. Intensitas Cahaya (Candela) versus Flash Hider (Variasi Buffle)

5.Analisa Penurunan Intensitas Cahaya

Data hasil pengujian intensitas cahaya, dengan menggunakan flash hider dan tanpa menggunakan flash hider, terjadi penurunan intensitas cahaya dengan nilai intensitas cahaya tanpa flash hider $=0,004$ candela dan 
TRANSMISI Volume 16 Nomor 12020

dengan flash hider(variasi buffle) $=0,0004$ candela, maka persentase penurunan nilai intensitas cahaya dihitung dengan rumus:

Persentase $=\frac{\text { Tanpa Flash Hider }- \text { Dengan Flash Hides }}{\text { Tanpa Flash Fider }} .100 \%$
Persentase $=\frac{0,004-0,0004}{0,004} .100 \%=90 \%$.

Dengan perhitungan yang sama, hasilnya ditunjukkan pada Tabel 10 .

Tabel 10. Penurunan Tingkat Intensitas Cahaya

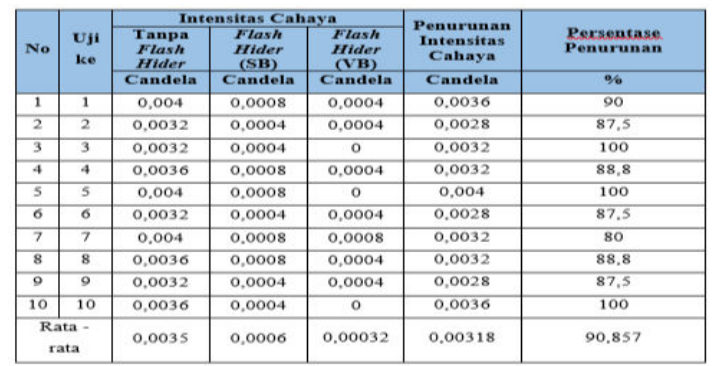

\section{Pembahasan}

Penggunaan peredam cahaya (flash hider) pada senapan serbu SS1-V1 dapat menurunkan besarnya intensitas cahaya (candela) di ujung laras. Hasil pengujian diperoleh rata-rata besarnya intensitas penerangan tanpa menggunakan flash hider adalah 8,9 Lux dan rata-rata intensitas cahaya adalah 0,0035 candela. Rata-rata intensitas penerangan dengan menggunakan flash hider (satu buffle) adalah 1,5 Lux dan untuk rata-rata besarnya intensitas cahaya adalah 0,0006candela. Rata-rata intensitas penerangan dengan menggunakan flash hider (variasi buffle) adalah 0,8 Lux dan rata-rata intensitas cahaya adalah 0,00032Candela.

Perhitungan besarnya tekanan gas di ujung laras senapan serbuSS1-V1 adalah 958,5888497 bar dan kecepatan pelor diujung laras adalah $989 \mathrm{~m} / \mathrm{dt}$. Sedangkan dengan menggunakan flash hider adalah 66,918 bar dan diperoleh besarnya kecepatan pelor diujung flash hideradalah $788,8715179 \mathrm{~m} / \mathrm{dt}$.Rata-rata persentase penurunan intensitas cahaya tanpa menggunakan flash hider dan dengan menggunakan flash hider (satu buffle) adalah sebesar 83,42 $\%$. Sedangkan untuk rata-rata persentase penurunan intensitas cahaya tanpa menggunakan flash hiderdan dengan menggunakan flash hider(variasi buffle) adalah sebesar $90,857 \%$.

\section{Kesimpulan}

1. Penurunan intensitas cahaya rata-rata sebesar $83,42 \%$ dengan menggunakan senapan serbu SS1-V1, Dimana pada penembakan tanpa menggunakan flash hiderdiperoleh hasil sebesar 0,0035 candela dan setelah menggunakan flash hider (satu buffle) diperoleh penurunan menjadi 0,0006 Candela. Sedangkan Penurunan intensitas cahaya rata-rata sebesar 90,857\% dengan menggunakan senapan serbu SS1-V1, di mana pada penembakan tanpa menggunakan flash hiderdiperoleh hasil sebesar 0,0035 candela dan setelah menggunakan flash hider (variasi buffle) diperoleh penurunan menjadi 0,00032 candela.

2. Perbandingan nilai persentase penurunan intensitas cahaya
3. pada saat penembakan menggunakan senjata SS1 V1 yang dipasang flash hider(satu buffle) sebesar 83,42\%, sedangkan apabila dipasang flashhider (variasi buffle) sebesar $90,857 \%$.

\section{Referensi}

[1] Francis W, Sears, Mark W. Zemansky \& Hugh D. 1993. Fisika Universitas, Edisi 6 Jilid 1 Penerbit Erlangga

[2] Krane, K. 1992. Fisika Modern. Jakarta: Universitas Indonesia Press.

[3] Oerlikon Buhrle AG. 1981. Oerlikon Pocket Book. Zurich.

[4] Putra, Yeffry Handoko. Besaran Cahaya, (Online), Bab4,(http://elib.unikom.ac.id/download.php?id=49473, Diakses tanggal 21 Juni 2016).

[5] Watkins, A.J. Electrical Instalation Calculations Volume 3. England: R. Parton.

[6] Zemansky, Sears. 1962. University Physics In One Volume. New York. 